\title{
Formation of a stalled early intermediate of pseudouridine synthesis monitored by real-time FRET
}

\author{
MARTIN HENGESBACH, ${ }^{1}$ FELIX VOIGTS-HOFFMANN, ${ }^{1,2,4}$ BENJAMIN HOFMANN, ${ }^{1,2}$ and MARK HELM ${ }^{1,3}$ \\ ${ }^{1}$ Institute of Pharmacy and Molecular Biotechnology, Department of Chemistry, Heidelberg University, 69120 Heidelberg, Germany \\ ${ }^{2}$ Master Program Molecular Biotechnology, Heidelberg University, 69120 Heidelberg, Germany \\ ${ }^{3}$ Institute of Pharmacy, Johannes Gutenberg-Universität Mainz, 55128 Mainz, Germany
}

\begin{abstract}
Pseudouridine is the most abundant of more than $\mathbf{1 0 0}$ chemically distinct natural ribonucleotide modifications. Its synthesis consists of an isomerization reaction of a uridine residue in the RNA chain and is catalyzed by pseudouridine synthases. The unusual reaction mechanism has become the object of renewed research effort, frequently involving replacement of the substrate uridines with 5-fluorouracil $\left(f^{5} U\right)$. $f^{5} U$ is known to be a potent inhibitor of pseudouridine synthase activity, but the effect varies among the target pseudouridine synthases. Derivatives of $f^{5} U$ have previously been detected, which are thought to be either hydrolysis products of covalent enzyme-RNA adducts, or isomerization intermediates. Here we describe the interaction of pseudouridine synthase 1 (Pus1p) with $f^{5} U$-containing tRNA. The interaction described is specific to Pus1p and position 27 in the tRNA anticodon stem, but the enzyme neither forms a covalent adduct nor stalls at a previously identified reaction intermediate of $f^{5} \mathrm{U}$. The $\mathrm{f}^{5} \mathrm{U} 27$ residue, as analyzed by a DNAzyme-based assay using TLC and mass spectrometry, displayed physicochemical properties unaltered by the reversible interaction with Pus1p. Thus, Pus1p binds an $f^{5} \mathrm{U}$-containing substrate, but, in contrast to other pseudouridine synthases, leaves the chemical structure of $f^{5} U$ unchanged. The specific, but nonproductive, interaction demonstrated here thus constitutes an intermediate of Pus turnover, stalled by the presence of $f^{5} U$ in an early state of catalysis. Observation of the interaction of Pus1p with fluorescence-labeled tRNA by a real-time readout of fluorescence anisotropy and FRET revealed significant structural distortion of $f^{5} U$-tRNA structure in the stalled intermediate state of pseudouridine catalysis.
\end{abstract}

Keywords: RNA modification; pseudouridine synthase; FRET; 5-fluorouridine; Pus inhibition; tRNA structure

\section{INTRODUCTION}

In addition to the four major nucleotides, the chemical complexity of naturally occurring RNA comprises a large variety of over 100 modified nucleotides, among which pseudouridine $(\Psi)$ is the most frequent. Its synthesis consists of an isomerization of uridine, and is catalyzed by pseudouridine synthases (Pus), a large and ubiquitous group of enzymes that falls into six families, named after their first identified representatives: TruA, TruB, TruD, RsuA, RluA, and Pus10 (Spedaliere et al. 2004; Gurha and Gupta 2008). The mechanistic details of catalysis, which does not require any cofactors, are subject to renewed interest (Spedaliere et al. 2004; Hamilton et al. 2005, 2006), as are the structural

${ }^{4}$ Present address: Swiss Federal Institute for Technology, Institute for Molecular Biology and Biophysics, 8093 Zürich, Switzerland.

Reprint requests to: Mark Helm, Institute of Pharmacy, Johannes Gutenberg-Universität Mainz, Staudinger Weg 5, 55128 Mainz, Germany; e-mail: mhelm@uni-mainz.de; fax: +49-6221-546430.

Article published online ahead of print. Article and publication date are at http://www.rnajournal.org/cgi/doi/10.1261/rna.1832510. effects of $\Psi$ on RNA by itself (Helm 2006). During isomerization of uridine to pseudouridine, the carbon-carbon bond of the anomeric ribose-carbon with the carbon 5 of the uracil is formed at the expense of the usual carbon-nitrogen glycosidic bond (Fig. 1A).

The mechanism is thought to involve a nucleophilic attack of the catalytic aspartate, either at the $\mathrm{C} 1$ of the ribose ("acylal mechanism") or-similar to the synthesis of thymidine from uracil-at the $\mathrm{C} 6$ of the pyrimidine ring. Following the Michael addition, the latter mechanism proceeds via a covalent intermediate referred to as "enolate." This undergoes rotation of the base and formation of the product pseudouridine (Foster et al. 2000; Spedaliere et al. 2004).

While the mechanism has so far eluded ultimate clarification, many insights have come from studies on the reaction with fluorouracil $\left(\mathrm{f}^{5} \mathrm{U}\right)$-containing RNA substrates (Fig. 1B). $\mathrm{f}^{5} \mathrm{U}$ was reported to form covalent adducts with certain pseudouridine synthases, such as e.g., TruA (Huang et al. 1998) and RluA (Spedaliere and Mueller 2004; Hamilton et al. 2005, 2006), that are stable toward SDS PAGE conditions, but can be disrupted by heating to yield a hydrated product 
A
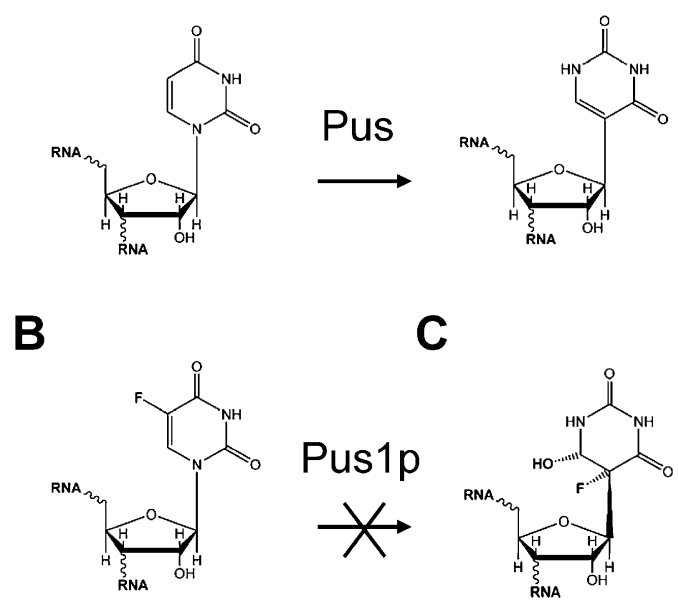

FIGURE 1. Chemical structures. (A) Uracil, which is converted to pseudouridine by pseudouridine synthases (Pus). (B) 5-Fluorouracil is a potent inhibitor of some pseudouridine synthases, some of which (except for the eukaryotic Puslp tested) form (C) 5-fluoro-6-hydroxypseudouridine $\left(\mathrm{f}^{5} h 0^{6} \Psi\right)$.

(Fig. 1C). In contrast, other pseudouridine synthases are not inhibited by $\mathrm{f}^{5} \mathrm{U}$-containing RNA, in which the $\mathrm{f}^{5} \mathrm{U}$ becomes hydrated and likely rearranged e.g., by Escherichia coli TruB (Spedaliere and Mueller 2004). Several crystallographic attempts have been made to trap covalent adducts, presumably between the conserved catalytic aspartate and the substrate. However, no covalent bond between nucleotide and the catalytic aspartate was observed in cocrystal structures of $\mathrm{f}^{5} \mathrm{U}$-containing RNAs and E. coli TruB (Hoang and FerréD’Amaré 2001), Thermotoga maritima TruB (Pan et al. 2003; Phannachet and Huang 2004), E. coli RluA (Hoang et al. 2006), and Pyrococcus furiosus Cbf5 (Duan et al. 2009; Liang et al. 2009) and the base was modeled as a hydrated, rearranged product of 5-fluoro-6-hydroxy-pseudouridine $\left(\mathrm{f}^{5} \mathrm{ho}^{6} \Psi\right)$ (Fig. 1C). In the case of RluA and Cbf5, this product may result from the X-ray sensitivity of a presumed covalent adduct, but was not unambiguously identified in the latter case.

Intriguingly, pseudouridine synthases share a structurally conserved catalytic domain, and therefore small differences in the active site geometry were suggested to account for the disparate behavior toward $\mathrm{f}^{5} \mathrm{U}$-containing RNAs (Spedaliere et al. 2004). However, the possibility was left open that, despite their sequence homologies, structural resemblances in the active center, and similarities in the catalytically active amino acids, pseudouridine synthases from different families may employ diverging catalytic strategies for the synthesis of pseudouridine (Spedaliere et al. 2004).

Pseudouridine synthase 1 (Pus1), a member of the TruA family, is a multisite and multisubstrate specific enzyme, which catalyzes pseudouridine formation at several positions of mammalian cytosolic and mitochondrial tRNAs, as well as in snRNA from various species (Arluison et al. 1998; Motorin et al. 1998; Arluison et al. 1999; Chen and Patton 1999;
Massenet et al. 1999; Chen and Patton 2000; Hellmuth et al. 2000; Patton and Padgett 2005; Patton et al. 2005; BehmAnsmant et al. 2006; Zhao et al. 2007; Sibert et al. 2008). These include positions in the anticodon stem of several tRNAs at positions 27 and 28. It has been shown that U27 is modified first, and depending on the substrate, U28 is modified less efficiently, apparently in an independent and slower second step (Motorin et al. 1998; Helm and Attardi 2004).

$\mathrm{f}^{5} \mathrm{U}$ has been used frequently in studies on cytotoxicity, and besides its inhibitory effect on thymidylate synthesis was shown to inhibit pseudouridinylation (Zhao and Yu 2007; Gustavsson and Ronne 2008; Hoskins and Butler 2008). These effects can possibly be attributed to three main mechanisms, affecting either the enzyme or the RNA structure. First, formation of a covalent adduct between $\mathrm{f}^{5} \mathrm{U}$ and the pseudouridine synthase renders the enzyme inactive, resulting in a decreased level of the respective activity available for cellular processes. Second, $\mathrm{f}^{5} \mathrm{U}$ may be noncovalently bound by pseudouridine synthases, but not processed, thus blocking the enzyme for other substrates. As a third possibility, the reaction may result in the presence of a modified base that does not exhibit the desired structural effects of the pseudouridine modification in the target RNA, therefore leading to a nonfunctional RNA.

In the first two cases, the effect is an inhibition of the enzyme that exceeds the extent expected from stoichiometric considerations. This is in good agreement with the work of (Zhao and Yu 2007), and is in line with their finding that there is no alteration of the behavior of $\mathrm{f}^{5} \mathrm{U}$ on the TLC systems used. In the presented work, the inhibitory effect of $\mathrm{f}^{5} \mathrm{U}$ on Puslp was used in order to make an enzyme-bound state of the substrate tRNA amenable to analysis by FRET.

We demonstrate here the detection of a nonproductive interaction between $\mathrm{f}^{5} \mathrm{U}$-containing tRNA and protein via measurement of fluorescence anisotropy and intramolecular FRET. We show that recombinant Pus1 proteins from mouse and from Saccharomyces cerevisiae specifically bind to human mitochondrial tRNA ${ }^{\mathrm{Leu}(\mathrm{CUN})}$ containing $\mathrm{f}^{5} \mathrm{U}$ at position 27 , thereby distorting parts of the tRNA structure. Unlike the previously characterized bacterial eponym of the TruA family, and the TruB and RluA pseudouridine synthases, formation of a covalent adduct with $\mathrm{f}^{5} \mathrm{U}$-containing tRNA was not detected. The nucleotide itself was found to be chemically unaltered by the interaction with Puslp. Fluorescence data obtained from the interaction with mitochondrial tRNA ${ }^{\text {Lys }}$ suggest that this constitutes an idiosyncratic feature typical of the interaction of Puslp with position 27 of various tRNAs.

\section{RESULTS}

\section{Synthesis of tRNAs that report structural changes by FRET}

Substrate tRNA constructs used in this study contain two fluorophores, namely the dyes Cy3 and Cy5, which form 
a well-characterized FRET-pair. FRET stands for fluorescence resonance energy transfer, and describes a distancedependent transfer of excitation energy from the so-called "green" or donor dye to the "red" acceptor dye, which is then emitted at the fluorescence wavelength of the red dye (Lilley and Wilson 2000; Coban et al. 2006). Because of the many factors affecting FRET-based calculation of absolute distances, the technique is widely used to assess relative changes in interdye distances.

Since such changes are best measured in the most dynamic range near the Förster radius $\mathrm{R}_{0}$, corresponding to the distance at 50\% energy transfer between a given dye pair, the attachment sites for Cy3 and Cy5 to human mitochondrial tRNA ${ }^{\mathrm{Leu}(\mathrm{CUN})}$ were chosen based on the X-ray structure of yeast tRNA ${ }^{\text {Phe }}$, such that the interdye distance would be around $53 \AA$, which is the $\mathrm{R}_{0}$ of the Cy3-Cy5 pair (Coban et al. 2006). Hence, Cy3 was attached via a spacer to the 5 -carbon of desoxyuracil at nucleotide 4, and Cy5 was attached to nucleotide 31 in the same way (details in Materials and Methods).

One-pot reactions of four-way splint ligations on the nanomole scale lead to isolated yields of $10 \%-15 \%$ (Kurschat et al. 2005; Hengesbach et al. 2008a). The communication of both dyes by FRET, as well as their anisotropy was assessed by bulk fluorescence spectroscopy. From the fluorescence spectra, FRET efficiencies $\left(E_{\mathrm{FRET}}\right)$ of $\sim 0.75$ for all tRNA ${ }^{\text {Leu(CUN) }}$ constructs were calculated as detailed in Material and Methods. This indicates that in the absence of modifying proteins, the constructs adopt a similar structure.

\section{Pseudouridine synthase 1 binds tRNA constructs with $U 27, C 27, f^{5} U 27$, and $f^{5} \mathrm{U} 28$ and distorts the $f^{5} \mathrm{U} 27$ substrate}

$\mathrm{U} 27$ and $\mathrm{f}^{5} \mathrm{U} 27$ derivatives of $\mathrm{RRNA}^{\mathrm{Leu}(\mathrm{CUN})}$ (shown in Fig. 2) were incubated in the presence of different molar excesses of recombinant Puslp, and $E_{\mathrm{FRET}}$ values were calculated from full spectra recorded at the time points indicated in Figure 3A. While $E_{\mathrm{FRET}}$ of U27-tRNA ${ }^{\mathrm{Leu}(\mathrm{CUN})}$ remained essentially invariant, $E_{\text {FRET }}$ of $f^{5} \mathrm{U} 27-\mathrm{tRNA}^{\mathrm{Leu}(\mathrm{CUN})}$ showed a strong decay during the first $10-20 \mathrm{~min}$ in the

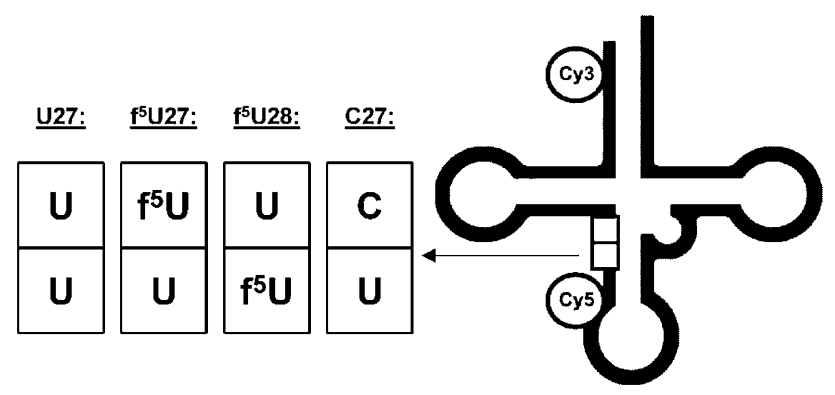

FIGURE 2. Schematic of the tRNA ${ }^{\mathrm{Leu}(\mathrm{CUN})}$ construct. The bases placed in positions 27 and 28 are indicated with their names used throughout the text.
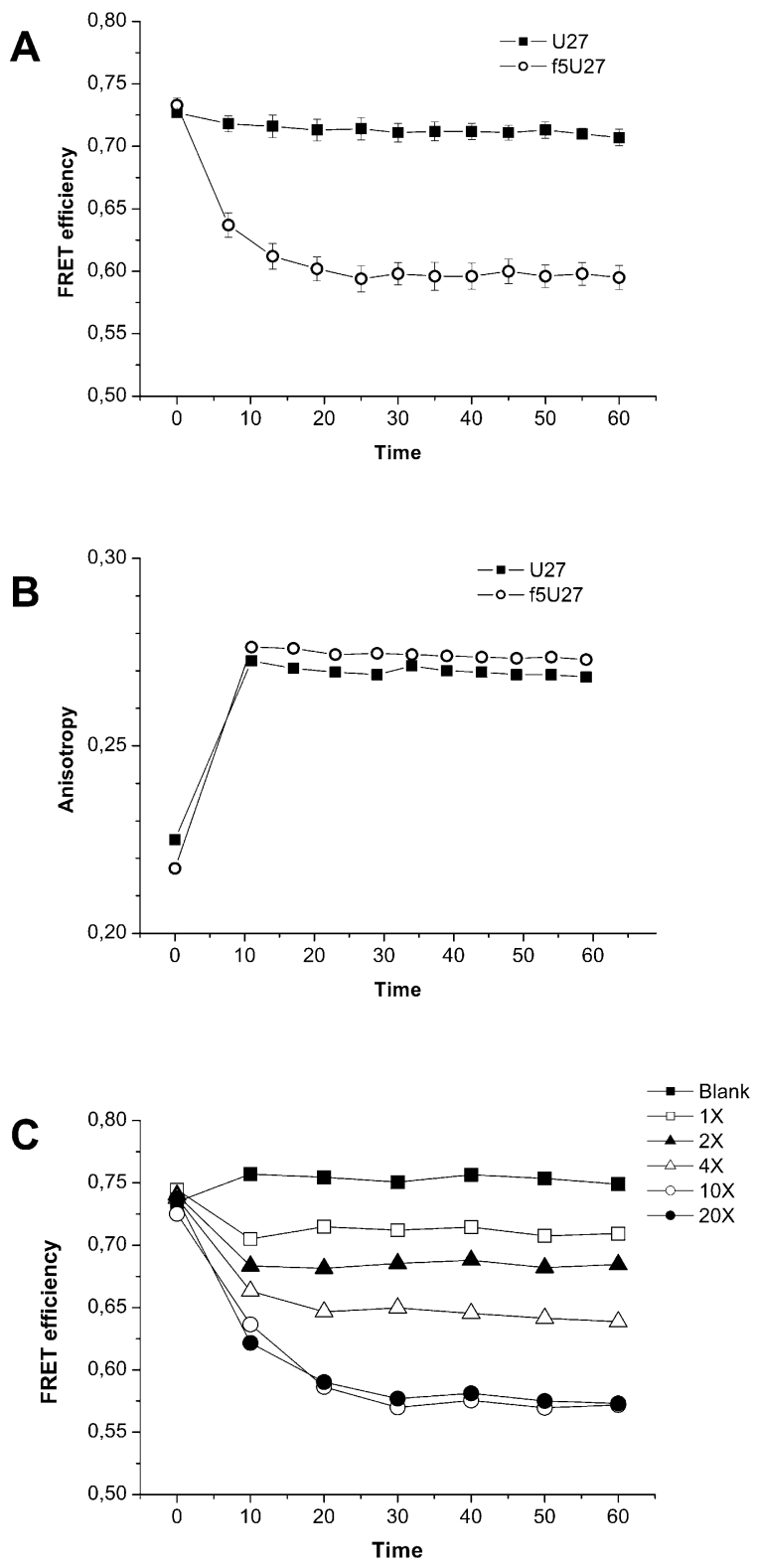

FIGURE 3. Fluorescence spectroscopy measurements of tRNA constructs during incubation with Puslp. (A) FRET efficiency for $\mathrm{f}^{5} \mathrm{U} 27$, but not for U27 construct decreases in the presence of Pus1p. (B) At the same time, the fluorescence anisotropy increases to a similar extent. $(C)$ The FRET decrease depends on the amount of Puslp used (different molar excesses indicated as " $\mathrm{X}$ ").

presence of a 20-fold excess of Pus1p, indicating the formation of a stable complex featuring an apparent structural distortion. The complexed $\mathrm{f}^{5} \mathrm{U} 27$ derivative subsequently remained stable in this low-FRET state over $40 \mathrm{~min}$. This stabilization and other evidence outlined below argue against the effect stemming from degradation. Upon incubation, the anisotropy of acceptor fluorescence for both constructs showed a significant increase (Fig. 3B), which was also observed for a $\mathrm{C} 27$ and an $\mathrm{f}^{5} \mathrm{U} 28$ derivative (discussed below). For $\mathrm{U} 27$ and $\mathrm{f}^{5} \mathrm{U} 27$, a titration experiment with increasing 
concentrations of Pus1 was conducted, which showed that the change in $E_{\mathrm{FRET}}$ correlated with the concentration of applied protein (Fig. 3C), as was the case for the increase in anisotropy for both constructs. The FRET decrease reached its half-maximum at a fourfold excess of Pus1p.

A number of control experiments were performed to verify that the tRNA's decrease in $E_{\mathrm{FRET}}$ was indeed specific to the interaction with Pus1p. Integrity of the Cy5 acceptor dye population was verified by comparison of direct excitation spectra taken before and after the incubation. Aliquots drawn before and after the incubation were submitted to denaturing PAGE. The gels were scanned with a fluorescence imaging system, which allows the detection of fmol quantities of dye-labeled RNA. Thus, the assessed degradation during incubation was consistently below $2 \%$, excluding any relevant effect on the $E_{\mathrm{FRET}}$ measurement. Of note, repurified constructs showed FRET efficiencies comparable to unincubated ones.

Significant changes in FRET efficiency or fluorescence anisotropy were observed neither in protein storage buffer alone, nor in the presence of bovine serum albumin. For comparison, $E_{\mathrm{FRET}}$ kinetics of tRNA ${ }^{\mathrm{Leu}(\mathrm{CUN})}$ were investigated upon incubation with a noncognate tRNA modification enzyme. In experiments with recombinant yeast $\mathrm{m}^{1} \mathrm{G}$ 9tRNA-methyltransferase Trm10p (Jackman et al. 2003), the $E_{\mathrm{FRET}}$ of $\mathrm{f}^{5} \mathrm{U} 27-\mathrm{tRNA}{ }^{\mathrm{Leu}(\mathrm{CUN})}$ did not significantly change (Fig. 4). Importantly, the decrease of FRET efficiency observed upon incubation of $\mathrm{f}^{5} \mathrm{U} 27-\mathrm{tRNA} \mathrm{Leu}^{\mathrm{LeUN})}$ with homologous Pus1p from mouse was similar to that observed for the yeast enzyme. These data establish that the observed time-dependent decrease of $E_{\mathrm{FRET}}$ in $\mathrm{f}^{5} \mathrm{U} 27$-tRNA is due to specific interaction of this tRNA with Puslp.

Further investigations into the specificity of this interesting interaction were conducted using derivatives of tRNA $^{\mathrm{Leu}(\mathrm{CUN})}$ featuring $\mathrm{f}^{5} \mathrm{U} 28$ or a $\mathrm{C} 27$, respectively. The

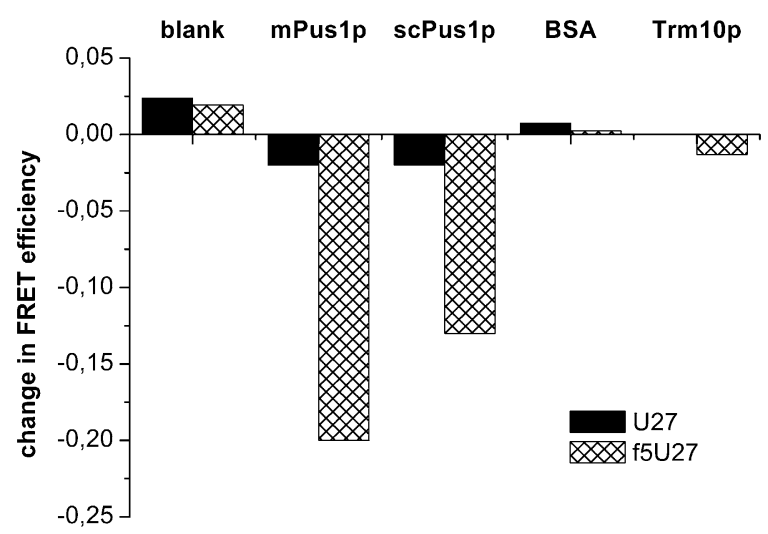

FIGURE 4. FRET efficiency responds to specific protein binding. Changes in FRET efficiency are shown for FRET-modified tRNA (black) and the $\mathrm{f}^{5} \mathrm{U}$-containing derivative (hatched) in the presence and absence of various proteins. The decrease in FRET efficiency is restricted to the eukaryotic Puslp homologs tested, and is specific to the $\mathrm{f}^{5} \mathrm{U} 27$ tRNA construct. latter constitutes a negative mutant, where the primary target residue of Pus1p, i.e., the U27 has been altered such that catalytic turnover at position 27 would be rendered impossible. Of note, a certain degree of structural distortion induced by the mutation itself is to be expected. The former derivative, $f^{5} \mathrm{U} 28$, was investigated to probe for a potential interaction of Puslp with its secondary target site 28. Both derivatives display a weak response in $E_{\mathrm{FRET}}$ (Fig. 5) similar to U27, indicating that the apparent structural distortion is observable only with $\mathrm{f}^{5} \mathrm{U}$ at position 27 .

Next, a different tRNA was investigated in order to gauge, whether the spectroscopic observations with $\mathrm{f}^{5} \mathrm{U} 27$ constitute an isolated case particular to human mitochondrial tRNA $^{\text {Leu(CUN) }}$, or a more general feature of Puslp. Mitochondrial tRNA ${ }^{\text {Lys }}$ has been extensively characterized in our lab, including interaction studies with Puslp. tRNA ${ }^{\text {Lys }}$ requires either the post-transcriptional modification $\mathrm{m}^{1} \mathrm{~A} 9$ or certain stabilizing mutations to achieve cloverleaf folding. In the absence of either, it adopts an extended hairpin structure (Helm et al. 1998), which prevents modification by Puslp in a manner comparable to that of tRNA ${ }^{\mathrm{Leu}(\mathrm{CUN})}$ (Helm and Attardi 2004; Voigts-Hoffmann et al. 2007). Hence, we here employ a tRNA ${ }^{\text {Lys }}$ construct containing a cloverleaf-stabilizing G50-C64 base pair exchange (Helm et al. 1998), in combination with a respective construct featuring the $\mathrm{f}^{5} \mathrm{U} 27$ residue. Remarkably, the behavior of this pair corresponds to that of the $\mathrm{U} 27-\mathrm{f}^{5} \mathrm{U} 27$ pair in the tRNA ${ }^{\text {Leu(UUR) }}$ context: while the U27 derivative shows a clear response in polarization, but little change in $E_{\mathrm{FRET}}$, the $\mathrm{f}^{5} \mathrm{U} 27$ derivative shows an equally strong response in polarization in addition to a strong and lasting decrease in $E_{\mathrm{FRET}}$ in the presence of Puslp (Fig. 5).

\section{Fluorophore-labeled tRNA ${ }^{\text {Leu(CUN) }}$ constructs are substrates for pseudouridine synthase 1}

While the substrate properties of fluorophore-labeled tRNA $^{\text {Lys }}$ constructs have previously been established (Voigts-Hoffmann et al. 2007), those of fluorophore-labeled tRNA ${ }^{\text {Leu(CUN) }}$ remained to be demonstrated. Thus, tRNA was recovered after spectral characterization and, after repurification by denaturing PAGE, the nucleotide at position 27 was analyzed by a site-specific post-labeling assay (Hengesbach et al. 2008b). As depicted in Figure 6, tRNA was annealed to a 10-23 DNAzyme designed to cleave between nucleotides A26 and U27, and the mixture was then submitted to temperature cycling in a PCR machine until quantitative cleavage was achieved. Because of the site- and sequencespecificity of the DNAzyme mediated cleavage, this assay does not allow analysis of $\mathrm{C} 27$ or of the residue 28 in any of the constructs. For constructs containing $\mathrm{U} 27$ or $\mathrm{f}^{5} \mathrm{U} 27$, free $5^{\prime}$-hydroxyl groups were quantitatively phosphorylated using $\gamma-\left[{ }^{32} \mathrm{P}\right]$-ATP and polynucleotide kinase. The reaction mixture was then submitted to DNase treatment to degrade the DNAzyme. The 3 '-fragment of the tRNA, now carrying 

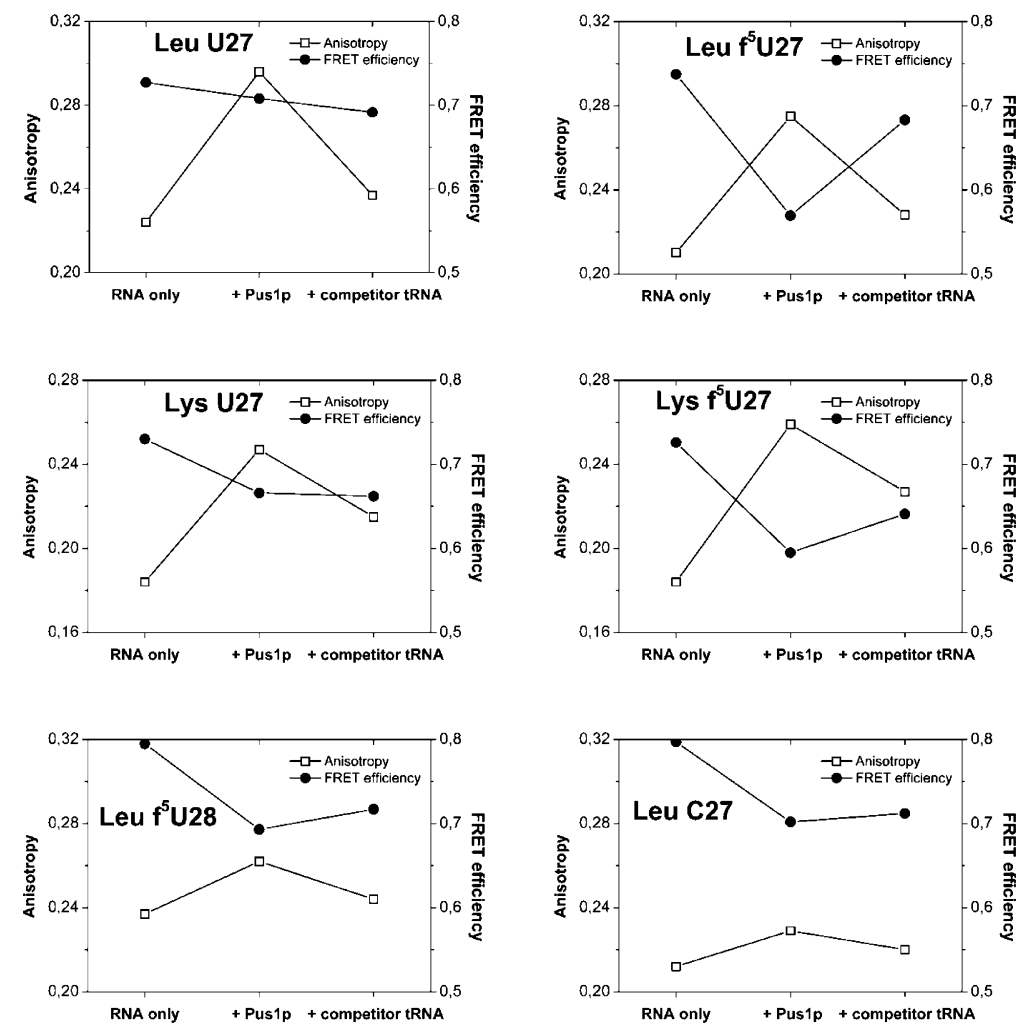

FIGURE 5. The concurrent recording of fluorescence anisotropy and FRET efficiency allows for assignment of structural distortion of the tRNA $(20 \mathrm{nM})$ during binding to the modifying enzyme. Anisotropy and FRET readings are plotted before addition of Puslp $\left(c_{\text {final }}=400 \mathrm{nM}\right)$ protein (indicated by "RNA only" on the $x$-axis), after 90 min incubation with Puslp, and after addition of an excess of unlabeled tRNA substrate $\left(c_{\text {final }}=8 \mu \mathrm{M}\right)$.

a $5^{\prime}-\left[{ }^{32} \mathrm{P}\right]$-phosphate-label on nucleotide 27 , was isolated by denaturing PAGE and digested to mononucleotides with nuclease P1. Analysis of this mixture by thin-layer chromatography (TLC), as shown in Figure $6 \mathrm{~B}$, revealed that uridine at position 27 is indeed converted to pseudouridine in good yield. For tRNA ${ }^{\text {Leu(CUN) }}$ this applied to both U27 ("wild-type": 38\% modification efficiency) and $\mathrm{U} 27-\mathrm{f}^{5} \mathrm{U} 28$ (53\% modification efficiency) constructs. The tRNA ${ }^{\text {Lys }}$ construct was modified to an extent of $34 \%$. Previous investigations indicate, that modification of $\mathrm{U} 28$ is negligible for the U27-U28 constructs under these conditions (Helm and Attardi 2004).

\section{Pus1p does not turn over $f^{5}$ U27-containing tRNA substrates}

Analysis of tRNAs containing $\mathrm{f}^{5} \mathrm{U} 27$ showed no detectable chemical alteration by TLC in any of altogether three different solvent systems, two of which are shown in Figure 6B. This strongly suggests that the chemical nature of the $\mathrm{f}^{5} \mathrm{U} 27$ residue remains unaffected by incubation with Pus1p. In addition, $\mathrm{f}^{5} \mathrm{U} 28$-containing tRNAs were efficiently modified at position 27 , showing that the mere presence of $f^{5} \mathrm{U}$ does not disturb Puslp binding or the enzymatic reaction. It is also clear that mechanistic conclusions drawn from the presented data concerning $\mathrm{f}^{5} \mathrm{U}$ at the primary Puslp target site 27 cannot automatically be applied to tRNAs containing $\mathrm{f}^{5} \mathrm{U}$ at the secondary target site 28 .

In order to further exclude alternative reaction products that may have escaped characterization of the $\mathrm{f}^{5} \mathrm{U} 27-\mathrm{Pus} 1 \mathrm{p}$ interaction by TLC, a 24mer RNA fragment ranging from U23 to A47 was excised using a tandem DNAzyme. This fragment spans the Cy5 dye attachment site, as well as the modification site. The fragment was purified by PAGE, eluted, and ethanol precipitated. After desalting with a ZipTip containing an RP-18 resin, the purified RNA was subjected to mass spectrometry analysis by MALDI. This included mixtures of (1) treated and untreated tRNA, as well as (2) $\mathrm{U} 27, \mathrm{f}^{5} \mathrm{U} 27$, and $\mathrm{f}^{5} \mathrm{U} 28$ constructs. Comparing untreated and treated $\mathrm{U} 27$ and $\mathrm{f}^{5} \mathrm{U} 27$ constructs, it could be shown that the apparent mass of the oligonucleotide is not altered upon incubation by Puslp, i.e., there was no formation of a hydrated or defluorinated

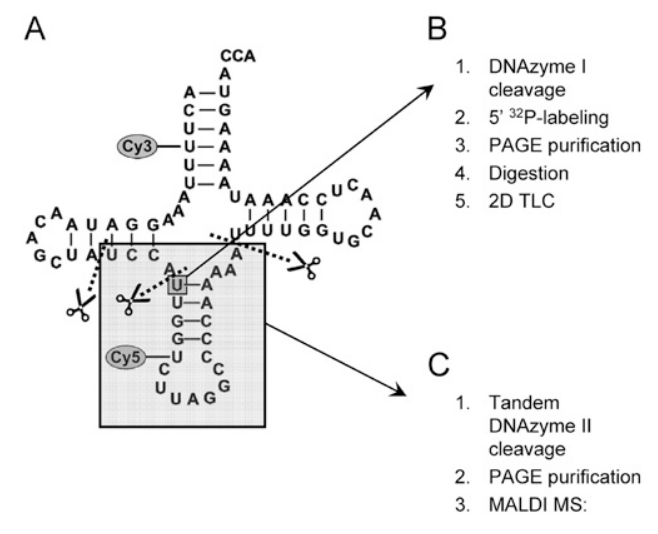

FIGURE 6. Assessing the chemical nature of the target base by two cooperative DNAzymebased methods. (A) Scheme of the FRET-labeled tRNA construct, which is cleaved by either of two DNAzymes. (B) Cleavage by DNAzyme I proceeds adjacent to nucleotide 27, and allows labeling and TLC analysis of the nucleotide 27, the $5^{\prime}$-terminal nucleotide of the downstream fragment. $(C)$ Double cleavage by tandem DNAzyme II produces a fragment that is subjected to MALDI mass spectrometry. 
product; this also holds true for the $\mathrm{f}^{5} \mathrm{U} 28$ construct (Fig. 6C).

\section{Pus1p forms a stable, but not a covalent adduct with $\mathrm{f}^{5} \mathrm{U}$-containing substrate IRNAs}

Aliquots of reaction mixtures containing one- or twofold excess of Pus1p over tRNA were loaded onto nondenaturing polyacrylamide gels without prior heating. As can be seen in Figure 7, all constructs tested showed formation of a complex with shifted mobility on the nondenaturing gel, but $\mathrm{f}^{5} \mathrm{U} 27$-containing tRNAs did so to a greater extent. So far, these findings are in keeping with the known behavior of Pus-RNA interactions. Because several other pseudouridine synthases have been reported to form covalent adducts or highly stable noncovalent complexes with RNA substrates containing $\mathrm{f}^{5} \mathrm{U}$, the same reaction mixtures were investigated by different denaturing PAGE systems with and without prior heating. Aliquots of $\mathrm{f}^{5} \mathrm{U} 27-\mathrm{tRNAs}$ in reaction mixtures with Puslp produce a single band on urea PAGE (Fig. 7B) and SDS-PAGE (data not shown). There is thus no evidence for a covalent complex between the tRNA and Pus1p. As a control, yeast tRNA ${ }^{\text {Phe }}$ carrying $\mathrm{f}^{5} \mathrm{U}$ at position 55 showed complex formation resistant to urea PAGE when incubated with Thermotoga maritima TruB (data not shown). When Puslp-treated $\mathrm{f}^{5} \mathrm{U}$-tRNA was repurified on denaturing urea PAGE and refolded, an $E_{\text {FRET }}$ very close to the original value was restored.

To further characterize the $\mathrm{f}^{5} \mathrm{U} 27-\mathrm{tRNA}$ complex with Pus1p, and to assess whether its formation was reversible, its behavior toward an excess of unlabeled, competing substrate was analyzed in our spectroscopic $E_{\text {FRET }}$ assay. After recording FRET kinetics over 60-90 min, a 400-fold molar

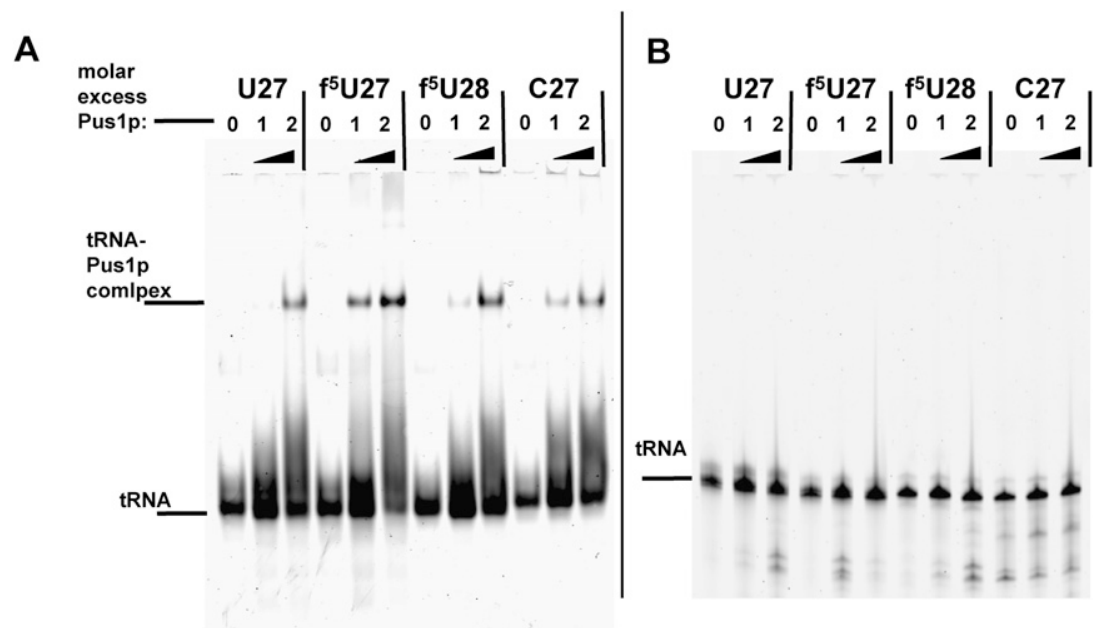

FIGURE 7. Gel electrophoresis of tRNA ${ }^{\text {Leu(CUN)}-P u s l p ~ c o m p l e x e s . ~}(A)$ Nondenaturing gel electrophoresis of reaction mixtures containing FRET-labeled tRNA constructs and Puslp shows a distinct band in addition to a smear, which migrates slower than the tRNA alone. The intensity of this band and the smear is highest for the $f^{5} \mathrm{U} 27$ construct. (B) Urea PAGE of aliquots from the same reaction mixtures shows single bands. excess of total tRNA from E. coli over FRET-labeled tRNA was added, and data acquisition was continued for another 60-90 min. Some tRNAs from E. coli carry a U27, and since E. coli does not possess modifying activities for pseudouridine formation at position 27 , this position serves as a substrate for Puslp. In contrast to samples containing no Pus1p or a U27 construct, the FRET efficiency increased for the $\mathrm{f}^{5} \mathrm{U}$-containing substrates upon addition of $E$. coli tRNA. The $E_{\text {FRET }}$ level almost recovered to the original values before addition of Pus1p (Fig. 8). At the same time, anisotropy for all constructs decreased to values before addition of Puslp (Fig. 5). This relaxation indicates that both $\mathrm{U} 27$ and $\mathrm{f}^{5} \mathrm{U} 27$ substrates were out-competed by the excess of unlabeled substrate tRNA, and that the interaction of the $\mathrm{f}^{5} \mathrm{U}$-containing substrate with Puslp must therefore be reversible. It thus argues against formation of a covalent $\mathrm{f}^{5} \mathrm{U}$ substrate-Puslp adduct of a type previously described in the literature. The reversibility of the Pus1p-tRNA interaction is further characterized by a titration of Pus1p shown in Figure 8. It is clearly apparent that the plateau level of the decreased $E_{\mathrm{FRET}}$ is strongly dependent on the concentration of Pus1p, while the subsequent relaxation to the original is $E_{\mathrm{FRET}}$ comparable.

\section{DISCUSSION}

\section{Fluorescently labeled tRNA constructs are substrates for Pus1p}

As previously shown for human mitochondrial tRNA ${ }^{\text {Lys }}$ (Voigts-Hoffmann et al. 2007), tRNA ${ }^{\text {Leu(CUN) }}$ labeled with Cy3 and Cy5 as a FRET pair is also a substrate for Pus1p. The comparable behavior of fluorescence anisotropy values in $\mathrm{U} 27$ and $\mathrm{f}^{5} \mathrm{U} 27$ constructs upon addition of Puslp indicates similarities in the mode of binding. In addition, competition experiments with excess unlabeled substrate tRNA show that the interaction is reversible in both cases as judged from fluorescence anisotropy. Together with the data derived from analysis of pseudouridine formation, the behavior of the system analyzed can be considered resembling the natural enzymatic turnover.

\section{FRET as a useful reporter for structural changes in tRNA}

By determining changes in FRET efficiency - and thus changes in spatial distance between the attachment sites within the tRNA-structural alterations of the substrate tRNA can be assessed. FRET of untreated samples remained stable even 


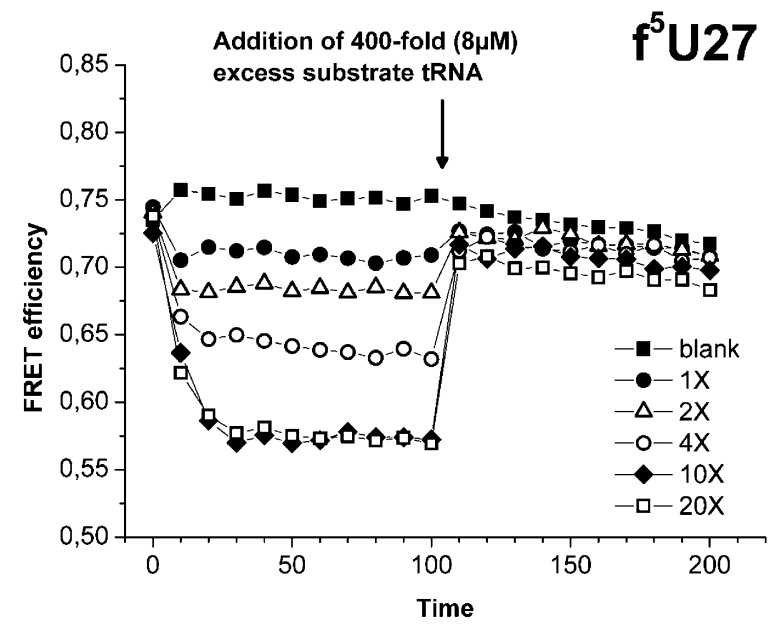

FIGURE 8. Kinetics of FRET efficiency of tRNA ${ }^{\mathrm{Leu}(\mathrm{CUN})} \mathrm{f}^{5} \mathrm{U} 27(c=$ $20 \mathrm{nM})$ after addition of Puslp $\left(c_{\text {final }}=400 \mathrm{nM}\right)$ at $t=0$. The distorting effect titrates with the excess of Puslp used (indicated as " $\mathrm{X}$ ") and is in all cases reversible to yield a FRET efficiency comparable to unbound tRNA. "Blank" indicates the control measurement of tRNA in the absence of protein.

over time periods of up to $3 \mathrm{~h}$, which shows that any changes in FRET are specific to the conditions tested. Whereas the $\mathrm{f}^{5} \mathrm{U}$-containing construct shows a significant decrease in FRET efficiency when binding to Pus1p, the U27 construct does not. Taking the change in fluorescence anisotropy into consideration, this strongly indicates a distortion of the $\mathrm{f}^{5} \mathrm{U}$ substrate by Puslp.

A two-step model of substrate binding by pseudouridine synthases was proposed (Kealey et al. 1994; Hur et al. 2006), separating the rapid binding of substrate RNA to the pseudouridine synthase from a slower flipping of the target base, aligning it in the catalytic pocket. The data presented here for the $\mathrm{f}^{5} \mathrm{U}$-tRNA support this model; the quick association of Puslp with the substrate is reflected in the fluorescence anisotropy, whereas distortion of the RNA is a slower process, which manifests in a significant decrease in FRET efficiency after $\sim 10$ min (Fig. 3). The difference of the fluorescence anisotropy and FRET kinetics during the first $15 \mathrm{~min}$ also shows that there is no significant contribution of the fluorophores' orientational freedom to the FRET effect in the system analyzed here. The fact that the $\mathrm{f}^{5} \mathrm{U} 27$ constructs of both tRNA ${ }^{\mathrm{Leu}(\mathrm{CUN})}$ and tRNA ${ }^{\text {Lys }}$ show decreasing $E_{\mathrm{FRET}}$ upon Puslp binding suggests that the structural distortion is not an isolated event of one particular tRNA. It will be interesting to investigate resemblances to, e.g., the $\lambda$-shaped tRNA structure of the modification intermediate of the archaeosine tRNA-guanine transglycosylase (Ishitani et al. 2003).

Our data suggest, that the structural distortion is not observed in the U27-tRNAs, because it is related to a step of the catalytic process distinct from binding, which is therefore not synchronized in the ensemble observed here. Because the introduction of $\mathrm{f}^{5} \mathrm{U} 27$ stalls the catalytic process at this step, a significant population of this intermediate accumulates, thus allowing its observation.

\section{Characterization of base modification by two cooperative DNAzyme-based approaches}

Due to the limited amounts of modified RNA available, sensitive methods are required to assess the chemical nature of the modification. In this study, two different approaches based on site-specific cleavage of the target RNA by DNAzymes are employed. The first method uses a 10-23 type DNAzyme to cleave adjacent to the base to be analyzed, making it available for post-labeling (Hengesbach et al. 2008b). This method is comparable in strategy and sensitivity to the method employing RNase $\mathrm{H}$ (Zhao and $\mathrm{Yu}$ 2004, 2007). The second strategy cleaves the target RNA using a construct consisting of two DNAzyme motifs in one sequence. This tandem DNAzyme makes a defined RNA fragment available to MALDI-TOF mass spectrometry. The productive combination of both methods allows for a thorough characterization of the modified base with high sensitivity in the picomole range.

\section{Interaction between Pus1p and the $f^{5} U$ substrate is not productive and does not lead to formation of a covalent adduct}

Determination of the physicochemical properties of $\mathrm{f}^{5} \mathrm{U}$ at position 27 in the tRNA showed that neither chromatographic behavior in three different systems, nor the apparent mass of the nucleotide of interest were changed upon incubation with Puslp. The complex formed by the $\mathrm{f}^{5} \mathrm{U} 27$-containing substrates was shown to be more stable compared to the U27 constructs under conditions of nondenaturing gel electrophoresis. However, urea and SDS PAGE analysis, as well as experiments where the $f^{5} \mathrm{U}$ containing substrate was released from Pus1p by addition of excess unlabeled substrate tRNA, show that the interaction does not stall at a covalent intermediate, but at an earlier step than previously reported. This noncovalent, nonproductive binding of $\mathrm{f}^{5} \mathrm{U}$ substrates may be an additional mechanism contributing to the inhibitory effect of 5 -fluorouracil observed in vivo on pseudouridine synthases (Gustavsson and Ronne 2008).

\section{Specificity of the formation of a distorted intermediate}

The structural distortion, as evidenced by a decrease in $E_{\mathrm{FRET}}$, was observed for two homologous Puslp enzymes, showing that this feature is not restricted to a single species and likely to be idiosyncratic for Puslp. The fact that two different tRNAs, i.e., tRNA ${ }^{\text {Lys }}$ and tRNA ${ }^{\text {Leu(CUN) }}$ behave similarly in terms of anisotropy and $E_{\mathrm{FRET}}$ suggests, that the distortion may be a feature of most substrate tRNAs. It thus 
appears to represent a mode of recognition by Puslp, which is general with respect to the tRNA, but site specific for $\mathrm{f}^{5} \mathrm{U}$-containing tRNAs. In contrast, our data do not yield insight into the mechanism of pseudouridine formation at position 28 of the same tRNAs.

\section{Summary and Outlook}

To our knowledge, this is the first FRET-based investigation of an RNA-protein complex involving a modification enzyme. We have shown here that FRET-labeled tRNAs provide an excellent means to address tRNA structure even in the presence of a modification enzyme. We could show by anisotropy and FRET that the interaction is specific for $\mathrm{f}^{5} \mathrm{U} 27-\mathrm{tRNA}$ and Pus1p, and by MALDI and TLC that it is nonproductive, thus representing a stalled and probably early intermediate of pseudouridine synthesis. It was shown that a substrate tRNA containing a 5-fluorouracil at the target base is bound to and distorted by pseudouridine synthase 1 , but does not form a covalent adduct with the protein. The fact that 5-fluorouracil is not turned over by Pus1p is in contrast to studies on certain other pseudouridine synthases, found to either form covalent abortive intermediates or to produce hydrated reaction products. The present study thus leads to the conclusion that the exact type of pseudouridine synthase and especially the structural details of the active site are critically important in determining at which step $\mathrm{f}^{5} \mathrm{U}$ inhibits pseudouridine formation by Pus enzymes.

This makes usage of $\mathrm{f}^{5} \mathrm{U}$ at the target nucleotide a valuable tool to trap the tRNA-protein complex at an intermediate of pseudouridine synthesis, whose apparently unusual tRNA structure, and possible resemblances to other structural intermediates of modification processes (Ishitani et al. 2003) can then be studied in more detail. Definition of the spectral properties of this stalled intermediate, as done here, should pave the way to single-molecule observations of the tRNA structural rearrangements accompanying catalysis in real time.

\section{MATERIALS AND METHODS}

\section{Preparation of recombinant enzymes}

Plasmids encoding recombinant modification enzymes were kindly provided by Henri Grosjean (Université Paris-Sud) (S. cerevisiae PUS1), Eric Phizicky (University of Rochester) and Jane E. Jackman (Ohio State University) (S. cerevisiae TRM10), and Jeff Patton (University of South Carolina) (mouse PUS1). Induction and purification was essentially performed as previously described (Arluison et al. 1998; Motorin et al. 1998; Chen and Patton 1999; Constantinesco et al. 1999; Jackman et al. 2003), with the modifications described below. The proteins were expressed in Rosetta(DE3)pLysS (Novagen). Cells were grown on LB medium supplemented with ampicillin (AMP, $100 \mu \mathrm{L} / \mathrm{mL}$ ) and chloramphenicol (CAM, 30 $\mu \mathrm{g} / \mathrm{mL}$ ) or with kanamycin (KAN, $34 \mu \mathrm{g} / \mathrm{mL}$ ) and CAM.
Preparatory cultures of $50 \mathrm{~mL} \mathrm{LB}$ medium with the appropriate antibiotics were inoculated with single colonies and incubated overnight at $37^{\circ} \mathrm{C}$. The main cultures (up to $1 \mathrm{~L}$ ) were inoculated with $20-35 \mathrm{~mL}$ of preparatory culture, and grown at $37^{\circ} \mathrm{C}$, with gentle agitation at $250 \mathrm{rpm}$. When $\mathrm{OD}_{600}$ reached 0.6 , protein expression was induced by addition of $1 \mathrm{mM}$ IPTG. For Puslp, temperature was reduced to $25^{\circ} \mathrm{C}$ prior to induction and the

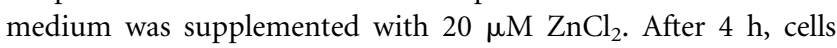
were pelleted, washed with $\mathrm{PBS}$, and stored at $-80^{\circ} \mathrm{C}$ after shock freezing in liquid nitrogen.

Purification of S. cerevisiae and mouse Puslp was performed on ice or at $4^{\circ} \mathrm{C}$. The pellet was resuspended in $15 \mathrm{~mL}$ buffer al $(50 \mathrm{mM}$ sodium phosphate at $\mathrm{pH} 8.0,200 \mathrm{mM} \mathrm{NaCl}, 1 \mathrm{mM}$ DTT, and $0.5 \mathrm{mg} / \mathrm{mL}$ dodecyl maltoside) (DM, Fluka), supplemented with $0.1 \%$ TritonX-100 and two complete miniprotease inhibitor tablets and lysed by sonication. Debris was pelleted at $40.000 \mathrm{~g}, 4^{\circ} \mathrm{C}$ for $20 \mathrm{~min}$. and the supernatant loaded onto a $1 \mathrm{~mL} \mathrm{Ni}^{2+}$-chelating column (Amersham, GE Healthcare). After washing with $30 \mathrm{~mL}$ of buffer a1 containing $42 \mathrm{mM}$ imidazole, the protein was eluted with $150 \mathrm{mM}$ imidazole in buffer a1. The protein was buffer-changed into buffer b1 (Tris- $\mathrm{HCl}$ at $\mathrm{pH} 8.5,10 \%$ glycerol, $1 \mathrm{mM} \mathrm{DTT,} 1 \mathrm{mM} \mathrm{MgCl}_{2}$, and $0.5 \mathrm{mg} / \mathrm{mL} \mathrm{DM}$ ) on PD-10 columns (Amersham), loaded on a $1 \mathrm{~mL}$ Resource Q anion exchange column (Amersham) and eluted with a linear gradient of $0-300 \mathrm{mM} \mathrm{NaCl}$ in buffer b1 over $14 \mathrm{~mL}$. Fractions with pure protein were identified by SDS-PAGE. Glycerol was added to $50 \%$ and aliquots were stored at $-20^{\circ} \mathrm{C}$ or shock frozen in liquid nitrogen and kept at $-80^{\circ} \mathrm{C}$. Mouse Puslp was eluted from the $\mathrm{Ni}^{2+}$-chelating column with a linear gradient of $0-300 \mathrm{mM}$ imidazole in buffer a1, and the pooled fractions were dialyzed into buffer $\mathrm{cl}(50 \mathrm{mM}$ Tris- $\mathrm{HCl}$ at $\mathrm{pH} 7.5,00 \mathrm{mM}$ $\mathrm{NaCl}, 10 \mathrm{mM} \mathrm{MgCl} 2,1 \mathrm{mM}$ DTT, and 25\% glycerol) overnight with one buffer change, and glycerol was added to $50 \%$ before freezing.

Purification of Trm10p from S. cerevisiae was carried out similarly, with buffer a2 $(20 \mathrm{mM}$ sodium phosphate at $\mathrm{pH} 8.0$, $10 \%$ glycerol, $4 \mathrm{mM} \mathrm{MgCl} 2,500 \mathrm{mM} \mathrm{NaCl}, 0.5 \mathrm{mM} \beta$-mercaptoethanol, and $1 \mathrm{mM}$ adenosine), supplemented with $20 \mathrm{mM}$ imidazole and protease inhibitors for lysis and $20 \mathrm{mM}$ imidazole for washing. After dialysis into buffer b2 $(20 \mathrm{mM}$ Tris- $\mathrm{HCl}$ at $\mathrm{pH}$ 7.5, $4 \mathrm{mM} \mathrm{MgCl}_{2}, 2 \mathrm{mM}$ EDTA, $55 \mathrm{mM} \mathrm{NaCl}, 1 \mathrm{mM}$ DTT, and $10 \%$ glycerol), pooled fractions were concentrated $(10 \mathrm{kDa}$ MWCO concentrators, Amicon, Billerica) and glycerol was added to $50 \%$ final concentration before freezing.

\section{SDS gel electrophoresis}

SDS-PAGE for analysis of protein purity and for studies on covalent interactions between $\mathrm{f}^{5} \mathrm{U} 27-\mathrm{tRNA}$ and Puslp was carried out on discontinuous mini-gels (resolving gel: $0.4 \mathrm{M}$ Tris- $\mathrm{HCl}$ at $\mathrm{pH} 8.8,10 \%$ acrylamide, $0.1 \%$ SDS; stacking gel: $0.125 \mathrm{M}$ Tris- $\mathrm{HCl}$ at $\mathrm{pH} 6.8,5 \%$ acrylamide, $0.1 \%$ SDS; electrophoresis buffer: $25 \mathrm{mM}$ Tris, $250 \mathrm{mM}$ glycine, and 0.1\% SDS). Samples were diluted at least twofold with loading buffer ( $63 \mathrm{mM}$ Tris- $\mathrm{HCl}$ at $\mathrm{pH} 6.8,25 \%$ glycerol, $2 \%$ SDS, and bromophenolblue). For protein purity analysis, but not for studies on covalent interaction, the samples were heated to $95^{\circ} \mathrm{C}$ for 4 min before loading. Gels were run at $200 \mathrm{~V}$ constant for $\sim 35 \mathrm{~min}$, washed with ultrapure water, stained with colloidal Coomassie and destained in water to enhance contrast. After $30 \mathrm{~min}$ incubation in gel drying solution, they were enclosed between two cellophane sheets and dried in a convection oven (GelAir, Bio-Rad). 


\section{Denaturing and nondenaturing polyacrylamide gel electrophoresis}

Two picomoles of each tRNA construct in $15 \mu \mathrm{L} \mathrm{H}_{2} \mathrm{O}$ were denatured for $3 \mathrm{~min}$ at $60^{\circ} \mathrm{C}$ and refolded by addition of $4 \mu \mathrm{L}$ 5X Pus1 buffer (0.1 M Tris- $\mathrm{HCl}$ at $\mathrm{pH} 8.0,10 \mathrm{mM} \mathrm{MgCl}_{2}, 0.1 \mathrm{M}$ ammonium acetate, $0.1 \mathrm{mM}$ EDTA, and $0.5 \mathrm{mM}$ DTT) by slow cooling to room temperature over $10 \mathrm{~min}$. Two or 4 pmol of Pus1p in $1 \mu \mathrm{L}$ were added and incubated at $30^{\circ} \mathrm{C}$ for $60 \mathrm{~min}$; for negative controls, only Pus1 storage buffer was added. Aliquots for nondenaturing gel electrophoresis were withdrawn and mixed with an equal volume of loading buffer containing $1 \mathrm{X}$ TBE and $60 \%$ glycerol. Aliquots for denaturing PAGE were withdrawn and mixed with an equal volume of loading buffer containing $1 \mathrm{X}$ TBE and $90 \%$ formamide. The samples were loaded onto $8 \%$ polyacrylamide gels without and with urea, respectively. Nondenaturing gels were run at $4^{\circ} \mathrm{C}$, denaturing gels at room temperature until a bromophenolblue-containing marker lane reached the lower $10 \%$ of the gel. Gels were stopped and immediately scanned on a Typhoon 9400 fluorescence scanner (GE Healthcare) for Cy3 and Cy5 fluorescence.

\section{Synthesis of tRNA derivatives}

Dye-labeled derivatives of human mitochondrial tRNALeu ${ }^{\mathrm{CUN}}$ were synthesized by a construction-kit approach based on splint ligation (Kurschat et al. 2005; Hengesbach et al. 2008a). Two of the fragments for each construct contained cyanine dyes, introduced site specifically by NHS-conjugation after solid phase synthesis.

For tRNA ${ }^{\mathrm{Leu}(\mathrm{CUN})}$ constructs, RNA oligonucleotides $5^{\prime}-\mathrm{ACdt}^{\mathrm{Cy} 3}$ UUUAAAGGAUA-3' ${ }^{\prime}, 5^{\prime}$-ACAGCUAUCCAUUG-3', $5^{\prime}$-Gdt ${ }^{\mathrm{Cy} 5} \mathrm{CU}$ UAGGCCCCAAAAAUUUUGGUGCAACUCCAAAUAAAAGUAC CA-3', and DNA template 5'-TGGTACTTTTATTTGGAGTTGCA CCAAAATTTTTGGGGCCTAAGACCAATGGATAGCTGTTATC CTTTAAAAGTTATAGTGAGTCGTATTAAGCTTCGCGCG-3' were used. For the tRNA ${ }^{\text {Lys }}$ construct, oligos AUUAACCUUUUAA, CA $\mathrm{Cdt}^{\mathrm{Cy} 3}$ GUAAAGCUAACUUAGC and GUdt ${ }^{\mathrm{Cy} 5}$ AAAGAUUAGGAG AACCAACACCUCCUUACAGUGACCA on the DNA template 5'-G GGTGGGTCTGCTTGGTCACTGTAAAGAGGTGTTGGTTCTC TTAATCTTTAACTTAAAAGGTTAATGCTAAGTTAGCTTTAC AGTGATTTTGGGTACC-3' were used. All these RNAs were obtained from IBA. At sites denoted dt, $5^{\prime}$-dimethoxytrityl-5-[ $N$-(trifluoroacetylaminohexyl)-3-acrylimido]-2' -deoxyuridine,3' -[(2-cyanoethyl)$(\mathrm{N}, \mathrm{N}$-diisopropyl)]-phosphoramidite was coupled during the synthesis instead of uridine phosphoramidites, replacing uridine in the sequence with a $2^{\prime}$-deoxythymidine, which carries a linear spacer of 11 atoms ending in a primary amino moiety, to which NHS derivatives of Cy3 and Cy5 dyes were conjugated post-synthetically. The respective conjugation sites are indicated as $\mathrm{dt}^{\mathrm{Cy} 3}$ and $\mathrm{dt}^{\mathrm{Cy} 5}$, respectively. RNA pACAGCUAUCCAf ${ }^{5} \mathrm{UG}\left(\mathrm{f}^{5} \mathrm{U}\right.$ stands for 5-fluorouracil; $p$ stands for $5^{\prime}$-phosphate) for tRNA ${ }^{\text {Leu(CUN) }}$ and RNA pAf ${ }^{5}$ UUAACCUUUUAA for tRNA ${ }^{\text {Lys }}$ were obtained from Dharmacon.

Oligonucleotides synthesized without a $5^{\prime}$-monophosphate were phosphorylated by incubation for $60 \mathrm{~min}$ at $37^{\circ} \mathrm{C}$ with $\mathrm{T} 4$ polynucleotide kinase $(0.75 \mathrm{u} / \mu \mathrm{L}$ T4-PNK, Fermentas) in buffer KL (50 $\mathrm{mM}$ Tris- $\mathrm{HCl}$ at $\mathrm{pH} 7.4$, and $10 \mathrm{mM} \mathrm{MgCl}_{2}$ ), supplemented with $5 \mathrm{mM}$ DTT and $2 \mathrm{mM}$ ATP. The phosphorylated RNA was used immediately in enzymatic ligation or stored at $-20^{\circ} \mathrm{C}$ until use. Splint ligation was performed as follows: stoichiometric amounts of the various respective RNA fragments $(5-10 \mu \mathrm{M})$ were hybridized to stoichiometric amounts of DNA template by heating to $75^{\circ} \mathrm{C}$ and slow cooling to room temperature over $10 \mathrm{~min}$ in buffer $\mathrm{KL}$ supplemented with $5 \mathrm{mM}$ DTT and $2 \mathrm{mM}$ ATP. T4 DNA ligase was added $(2 \mathrm{u} / \mu \mathrm{L})$ and ligation was carried out overnight at $16^{\circ} \mathrm{C}$. Template DNA was removed by addition of $0.02-0.1 \mathrm{u} / \mu \mathrm{L}$ DNase I followed by $15 \mathrm{~min}$ incubation at $37^{\circ} \mathrm{C}$. RNAs were purified by denaturing PAGE, identified by imaging Cy5 fluorescence with a Typhoon scanner (GE Healthcare), eluted from the gel, and precipitated with ethanol. Concentrations were calculated from absorption at $254 \mathrm{~nm}$, as determined on a Nanodrop ND1000 spectrometer.

\section{Modification of tRNA with Pus1p}

Before addition of protein, tRNA samples were denatured and refolded in Pus1 buffer as described above. Derivatives of tRNA carrying Cy3 and Cy5 $(0.5 \mu \mathrm{M})$ and $\mathrm{U} 27$ or $\mathrm{f}^{5} \mathrm{U} 27$, respectively, were incubated with 0.5 equivalents of $S$. cerevisiae Pus1p, as determined by UV absorbance and Bradford assay, respectively, for $30 \mathrm{~min}$ at $30^{\circ} \mathrm{C}$ in Pusl buffer.

\section{DNAzyme-based position specific modification assay}

Site-specific modification analysis was achieved by sequencedirected cleavage with a 10-23 type DNAzyme I designed (sequence for tRNA ${ }^{\mathrm{Leu}(\mathrm{CUN})}$ : 5'-AAAATTTTTGGGGCCTAAGACC AAGGCTAGCTACAACGAGGATAGCTGTTATCCTTTAA-3' ${ }^{\prime}$, sequence for tRNA ${ }^{\text {Lys }}$ : GGTTCTCTTAATCTTTAACTTAAAAGGTT AAGGCTAGCTACAACGAGCTAAGTTAGCTTTACAGTG from IBA) to cut between nucleotides 26 and 27 , followed by 5 '-labeling, nuclease P1 digestion, TLC, and autoradiography on phosphorimager plates. Protein was removed from the modification reaction mixture by extraction with two times two volumes of watersaturated phenol and two times five volumes of water-saturated diethylether to remove contaminant phenol from the solution. After evaporation of the diethylether under ambient conditions, the RNA was precipitated with ethanol. Modified or control tRNA with ten equivalents of DNAzyme was heated to $80^{\circ} \mathrm{C}$ for $2 \mathrm{~min}$ in DNAzyme buffer (100 mM Tris- $\mathrm{HCl}$ at $\mathrm{pH} 7.5,150 \mathrm{mM} \mathrm{NaCl}$, and $10 \mathrm{mM} \mathrm{MgCl}_{2}$ ), cooled to $37^{\circ} \mathrm{C}$ at $-0.3^{\circ} \mathrm{C} / \mathrm{min}$, and incubated at $37^{\circ} \mathrm{C}$ for $5 \mathrm{~min}$ in a PCR machine. This cycle was repeated 10 times, which produced complete and specific cleavage of the target tRNA between nucleotides 26 and 27. The free $5^{\prime} \mathrm{OH}$ on nucleotide 27 generated by DNAzyme cleavage was phosphorylated using T4 polynucleotide kinase. An equal volume of T4-PNK forward reaction buffer (Fermentas) supplemented with $0.1 \mathrm{mM}$ ATP, $1 \mu \mathrm{L}\left[\gamma^{32}{ }^{32} \mathrm{P}\right]$-ATP $(10 \mu \mathrm{Ci} / \mu \mathrm{L})$, and $0.5 \mathrm{u} / \mu \mathrm{L}$ T4-PNK was added to the cleavage reaction and incubated for $60 \mathrm{~min}$ at $37^{\circ} \mathrm{C}$. The DNAzyme was degraded with $0.025 \mathrm{u} / \mu \mathrm{L}$ of DNase I during $15 \mathrm{~min}$ of incubation at $37^{\circ} \mathrm{C}$ to facilitate purification of the $3^{\prime}$-terminal tRNA fragments on a $20 \%$ denaturing polyacrylamide gel. Fragments were identified by autoradiography and fluorescence imaging, excised, eluted, and precipitated as described above, resuspended in $20 \mathrm{mM}$ ammonium acetate at $\mathrm{pH} 5.3$ containing $1.0 \mu \mathrm{g} / \mu \mathrm{L}$ of $E$. coli total tRNA as carrier, and digested to $5^{\prime}$ mononucleotides with nuclease $\mathrm{P} 1$ overnight at room temperature. Thin layer chromatography was performed on 10 or $20 \mathrm{~cm}$ Merck cellulose TLC plates with buffer A (70\% isobutyric acid, $28.9 \%$ $\mathrm{H}_{2} \mathrm{O}, 1.1 \%$ ammonia [25\%] v/v/v), buffer B (70\% isopropanol, 
$15 \%$ conc. $\left.\mathrm{HCl}, 15 \% \mathrm{H}_{2} \mathrm{O}, \mathrm{v} / \mathrm{v} / \mathrm{v}\right)$, and buffer $\mathrm{C}(60 \% \mathrm{w} / \mathrm{v}$ ammonium sulfate, $2 \% \mathrm{v} / \mathrm{v} n$-propanol, $100 \mathrm{mM}$ phosphate buffer at pH 7.4) (Keith 1995; Grosjean et al. 2007). Radiolabeled nucleotides were visualized by autoradiography on phosphorimager screens and quantified by peak volume integration with the software Imagequant 5.2 (Molecular Dynamics, GE). Retention characteristics of 5-fluorouracil mononucleotides on two-dimensional TLC were identified by chromatography of $10 \mu \mathrm{g}$ digested $E$. coli total tRNA, mixed with $5^{\prime}{ }^{32} \mathrm{P} 5$-fluorouracil mononucleotides on $10 \times 10 \mathrm{~cm}^{2}$ cellulose TLC plates $\mathrm{F}_{254}$ (Merck), which contain a fluorescent dye. Radioactively labeled 5-fluorouracil mononucleotides were obtained from untreated $\mathrm{f}^{5} \mathrm{U} 27 \mathrm{tRNA} \mathrm{Leu}^{\mathrm{LeUN})}$ as described above. Radioactivity was visualized by autoradiography, while nonradioactive nucleotides, present in much greater amounts, were identified as dark spots during UV irradiation, as they quench the fluorescence of the $\mathrm{F}_{254}$ plates. The two images were overlaid according to two radioactive and colored markers.

\section{Fragment isolation by tandem DNAzyme cleavage}

In order to further clarify the physicochemical properties of the modified base, a 24-nucleotide fragment was excised from Pus1ptreated or untreated full-length tRNA with and without $f^{5} \mathrm{U}$, respectively, and subjected to MALDI-TOF mass spectrometry. Modification was carried out as described above, and protein was removed by extraction with 1 vol water-saturated phenol (2X) and 2-3 vol water-saturated diethylether (3X). The tandem DNAzyme II (sequence: 5' -TTGGAGTTGCACCAAAAGGCTAGCTACAACG ATTTTGGGGCCTAAGACCAATGGAGGCTAGCTACAACGAAG CTGTTATCCTTTAAAAGT-3'; IBA) was designed with cleavage sites targeted between A22 and U23, and between A47 and U48. Cleavage was carried out as described above for the post-labeling assay. The DNAzyme was removed by denaturing PA gel electrophoresis. The fragment carrying the Cy5 dye was identified by Typhoon fluorescence imaging, excised from the gel, and eluted in $0.5 \mathrm{M}$ ammonium acetate overnight. The RNA was ethanol precipitated, and purified by Millex RP-18 ZipTips (Millipore) with elution in acetonitrile. The fragment was subjected to MALDI-TOF mass spectrometry on a Bruker Daltonics BiFlex III (Bruker Daltonic), using an internal oligonucleotide standard (Bruker, No. 206200) with masses of 3645.4, 6117.0, and 9191.0 $\mathrm{Da}$ as calibration source. Expected masses were calculated using ChemDraw, including both a $5^{\prime}$-hydroxyl group and a $2^{\prime}-3^{\prime}$ cyclic phosphate from DNAzyme cleavage.

\section{Fluorescence spectroscopy}

In order to determine the orientational freedom of the tRNA, fluorescence anisotropy, in addition to FRET, was measured using a TECAN safire ${ }^{2}$ plate reader (Tecan). For these measurements, CoStar 96-well plates (Corning) with darkened walls were used. tRNAs were refolded in $1 \mathrm{X}$ Pus buffer by denaturing at $60^{\circ} \mathrm{C}$ for $3 \mathrm{~min}$ and slow refolding to room temperature over $>10 \mathrm{~min}$. Solutions of $21 \mathrm{nM}$ tRNA ( $2 \mathrm{pmol}$ ) were prepared in $95 \mu \mathrm{L}$, and FRET, as well as anisotropy, were measured. Five microliters of glycerol-free Pus1p solution of different concentrations (or glycerolfree storage buffer only as negative control) were added to achieve the different molar excesses described. FRET and anisotropy were measured either alternating or in an automated kinetics mode. The temperature during all measurements was $28 \pm 1^{\circ} \mathrm{C}$.
The measurement settings for anisotropy were: excitation wavelength $635 \mathrm{~nm}$, emission wavelength $680 \mathrm{~nm}$, emission bandwidth $10 \mathrm{~nm}, 50$ reads per well, and $50 \mathrm{~ms}$ between move and flash. As only relative changes are being discussed, a $G$ factor accounting for different orientational sensitivity differences was not determined experimentally and thus not introduced into the calculation. Anisotropy was calculated using the Tecan X-fluor software.

Measurement settings for FRET: Excitation wavelength: $530 \mathrm{~nm}$ with 10-nm bandwidth, emission wavelength scan from 555 to $720 \mathrm{~nm}$ (10 nm bandwidth) with 1-nm steps and 2-ms integration per data point; averaged over 2 reads per well. FRET efficiency was calculated from the average fluorescence intensity from five data points around the intensity maximum (Cy3: 566-570 nM, Cy5: 668-672 nM). FRET was calculated using donor and acceptor emission intensities upon donor excitation, where $E_{\mathrm{FRET}}=I_{\mathrm{A}} /\left(I_{\mathrm{D}}+I_{\mathrm{A}}\right)$.

For out-competing experiments, the solution containing $20 \mathrm{nM}$ substrate tRNA and different concentrations of Pus1p after $90 \mathrm{~min}$ was adjusted to contain $8 \mu \mathrm{M}$ total tRNA from E. coli (Roche) in $1 \mathrm{X}$ Pus buffer. FRET kinetics were measured continuously over $90 \mathrm{~min}$.

\section{ACKNOWLEDGMENTS}

We thank Heiko Rudy for mass spectrometry measurements and Roman Teimer for unpublished data. We thank Henri Grosjean, Eric Phizicky, Jane E. Jackman, and Jeff Patton for providing plasmids, and Andres Jäschke for constant support. M. Hengesbach was funded by the Landesgraduiertenförderung Baden-Württemberg. M. Helm acknowledges funding by the DFG (HE 3397/3).

Received July 17, 2009; accepted December 3, 2009.

\section{REFERENCES}

Arluison V, Hountondji C, Robert B, Grosjean H. 1998. Transfer RNA-pseudouridine synthetase Pus1 of Saccharomyces cerevisiae contains one atom of zinc essential for its native conformation and tRNA recognition. Biochemistry 37: 7268-7276.

Arluison V, Buckle M, Grosjean H. 1999. Pseudouridine synthetase Pus1 of Saccharomyces cerevisiae: Kinetic characterisation, tRNA structural requirement and real-time analysis of its complex with tRNA. J Mol Biol 289: 491-502.

Behm-Ansmant I, Massenet S, Immel F, Patton JR, Motorin Y, Branlant C. 2006. A previously unidentified activity of yeast and mouse RNA:pseudouridine synthases 1 (Pus1p) on tRNAs. RNA 12: $1583-1593$.

Chen J, Patton JR. 1999. Cloning and characterization of a mammalian pseudouridine synthase. RNA 5: 409-419.

Chen J, Patton JR. 2000. Mouse pseudouridine synthase 1: Gene structure and alternative splicing of pre-mRNA. Biochem J 352: 465-473.

Coban O, Lamb DC, Zaychikov E, Heumann H, Nienhaus GU. 2006. Conformational heterogeneity in RNA polymerase observed by single-pair FRET microscopy. Biophys J 90: 4605-4617.

Constantinesco F, Motorin Y, Grosjean H. 1999. Characterization and enzymatic properties of tRNA(guanine $26, N^{2}, N^{2}$ )-dimethyltransferase (Trm1p) from Pyrococcus furiosus. J Mol Biol 291: 375392.

Duan J, Li L, Lu J, Wang W, Ye K. 2009. Structural mechanism of substrate RNA recruitment in H/ACA RNA-guided pseudouridine synthase. Mol Cell 34: 427-439. 
Foster PG, Huang L, Santi DV, Stroud RM. 2000. The structural basis for tRNA recognition and pseudouridine formation by pseudouridine synthase I. Nat Struct Biol 7: 23-27.

Grosjean H, Droogmans L, Roovers M, Keith G. 2007. Detection of enzymatic activity of transfer RNA modification enzymes using radiolabeled tRNA substrates. Methods Enzymol 425: 55-101.

Gurha P, Gupta R. 2008. Archaeal Pus10 proteins can produce both pseudouridine 54 and 55 in tRNA. RNA 14: 2521-2527.

Gustavsson M, Ronne H. 2008. Evidence that tRNA modifying enzymes are important in vivo targets for 5 -fluorouracil in yeast. RNA 14: 666-674.

Hamilton CS, Spedaliere CJ, Ginter JM, Johnston MV, Mueller EG. 2005. The roles of the essential Asp- 48 and highly conserved His- 43 elucidated by the $\mathrm{pH}$ dependence of the pseudouridine synthase TruB. Arch Biochem Biophys 433: 322-334.

Hamilton CS, Greco TM, Vizthum CA, Ginter JM, Johnston MV, Mueller EG. 2006. Mechanistic investigations of the pseudouridine synthase RluA using RNA containing 5-fluorouridine. Biochemistry 45: 12029-12038.

Hellmuth K, Grosjean H, Motorin Y, Deinert K, Hurt E, Simos G. 2000. Cloning and characterization of the Schizosaccharomyces pombe tRNA:pseudouridine synthase Pus1p. Nucleic Acids Res 28: 4604-4610.

Helm M. 2006. Post-transcriptional nucleotide modification and alternative folding of RNA. Nucleic Acids Res 34: 721-733.

Helm M, Attardi G. 2004. Nuclear control of cloverleaf structure of human mitochondrial tRNA(Lys). J Mol Biol 337: 545-560.

Helm M, Brule H, Degoul F, Cepanec C, Leroux JP, Giege R, Florentz C. 1998. The presence of modified nucleotides is required for cloverleaf folding of a human mitochondrial tRNA. Nucleic Acids Res 26: 1636-1643.

Hengesbach M, Kobitski A, Voigts-Hoffmann F, Frauer C, Nienhaus GU, Helm M. 2008a. RNA intramolecular dynamics by single-molecule FRET. In Current protocols in nucleic acid chemistry. pp. 11.12.1-11.12.22. Wiley, New York.

Hengesbach M, Meusburger M, Lyko F, Helm M. 2008b. Use of DNAzymes for site-specific analysis of ribonucleotide modifications. RNA 14: 180-187.

Hoang C, Ferré-D'Amaré AR. 2001. Cocrystal structure of a tRNA $\Psi 55$ pseudouridine synthase: Nucleotide flipping by an RNAmodifying enzyme. Cell 107: 929-939.

Hoang C, Chen J, Vizthum CA, Kandel JM, Hamilton CS, Mueller EG, Ferré-D'Amaré AR. 2006. Crystal structure of pseudouridine synthase RluA: Indirect sequence readout through protein-induced RNA structure. Mol Cell 24: 535-545.

Hoskins J, Butler JS. 2008. RNA-based 5-fluorouracil toxicity requires the pseudouridylation activity of Cbf5p. Genetics 179: 323-330.

Huang L, Pookanjanatavip M, Gu X, Santi DV. 1998. A conserved aspartate of tRNA pseudouridine synthase is essential for activity and a probable nucleophilic catalyst. Biochemistry 37: 344-351.

Hur S, Stroud RM, Finer-Moore J. 2006. Substrate recognition by RNA 5-methyluridine methyltransferases and pseudouridine synthases: A structural perspective. J Biol Chem 281: 38969-38973.

Ishitani R, Nureki O, Nameki N, Okada N, Nishimura S, Yokoyama S. 2003. Alternative tertiary structure of tRNA for recognition by a post-transcriptional modification enzyme. Cell 113: 383-394.

Jackman JE, Montange RK, Malik HS, Phizicky EM. 2003. Identification of the yeast gene encoding the tRNA m1G methyltransferase responsible for modification at position 9. RNA 9: 574-585.

Kealey JT, Gu X, Santi DV. 1994. Enzymatic mechanism of tRNA ( $\left.{ }^{5} \mathrm{U} 54\right)$ methyltransferase. Biochimie 76: 1133-1142.
Keith G. 1995. Mobilities of modified ribonucleotides on twodimensional cellulose thin-layer chromatography. Biochimie 77: $142-144$

Kurschat WC, Muller J, Wombacher R, Helm M. 2005. Optimizing splinted ligation of highly structured small RNAs. RNA 11: 19091914.

Liang B, Zhou J, Kahen E, Terns RM, Terns MP, Li H. 2009. Structure of a functional ribonucleoprotein pseudouridine synthase bound to a substrate RNA. Nat Struct Mol Biol 16: 740-746.

Lilley DM, Wilson TJ. 2000. Fluorescence resonance energy transfer as a structural tool for nucleic acids. Curr Opin Chem Biol 4: 507517.

Massenet S, Motorin Y, Lafontaine DL, Hurt EC, Grosjean H, Branlant C. 1999. Pseudouridine mapping in the Saccharomyces cerevisiae spliceosomal U small nuclear RNAs (snRNAs) reveals that pseudouridine synthase puslp exhibits a dual substrate specificity for U2 snRNA and tRNA. Mol Cell Biol 19: 21422154.

Motorin Y, Keith G, Simon C, Foiret D, Simos G, Hurt E, Grosjean H. 1998. The yeast tRNA:pseudouridine synthase Puslp displays a multisite substrate specificity. RNA 4: 856-869.

Pan H, Agarwalla S, Moustakas DT, Finer-Moore J, Stroud RM. 2003. Structure of tRNA pseudouridine synthase TruB and its RNA complex: RNA recognition through a combination of rigid docking and induced fit. Proc Natl Acad Sci 100: 12648-12653.

Patton JR, Padgett RW. 2005. Pseudouridine modification in Caenorhabditis elegans spliceosomal snRNAs: Unique modifications are found in regions involved in snRNA-snRNA interactions. BMC Mol Biol 6. doi: 10.1186/1471-2199-6-20.

Patton JR, Bykhovskaya Y, Mengesha E, Bertolotto C, FischelGhodsian N. 2005. Mitochondrial myopathy and sideroblastic anemia (MLASA): Missense mutation in the pseudouridine synthase 1 (PUS1) gene is associated with the loss of tRNA pseudouridylation. J Biol Chem 280: 19823-19828.

Phannachet K, Huang RH. 2004. Conformational change of pseudouridine 55 synthase upon its association with RNA substrate. Nucleic Acids Res 32: 1422-1429.

Sibert BS, Fischel-Ghodsian N, Patton JR. 2008. Partial activity is seen with many substitutions of highly conserved active site residues in human Pseudouridine synthase 1. RNA 14: 1895-1906.

Spedaliere CJ, Mueller EG. 2004. Not all pseudouridine synthases are potently inhibited by RNA containing 5-fluorouridine. RNA 10: 192-199.

Spedaliere CJ, Ginter JM, Johnston MV, Mueller EG. 2004. The pseudouridine synthases: Revisiting a mechanism that seemed settled. J Am Chem Soc 126: 12758-12759.

Voigts-Hoffmann F, Hengesbach M, Kobitski AY, van Aerschot A, Herdewijn P, Nienhaus GU, Helm M. 2007. A methyl group controls conformational equilibrium in human mitochondrial tRNA $^{\text {Lys }}$. J Am Chem Soc 129: 13382-13383.

Zhao X, Yu YT. 2004. Detection and quantitation of RNA base modifications. RNA 10: 996-1002.

Zhao X, Yu YT. 2007. Incorporation of 5-fluorouracil into U2 snRNA blocks pseudouridylation and pre-mRNA splicing in vivo. Nucleic Acids Res 35: 550-558.

Zhao X, Patton JR, Ghosh SK, Fischel-Ghodsian N, Shen L, Spanjaard RA. 2007. Pus3p- and Pus1p-dependent pseudouridylation of steroid receptor RNA activator controls a functional switch that regulates nuclear receptor signaling. Mol Endocrinol 21: 686-699. 

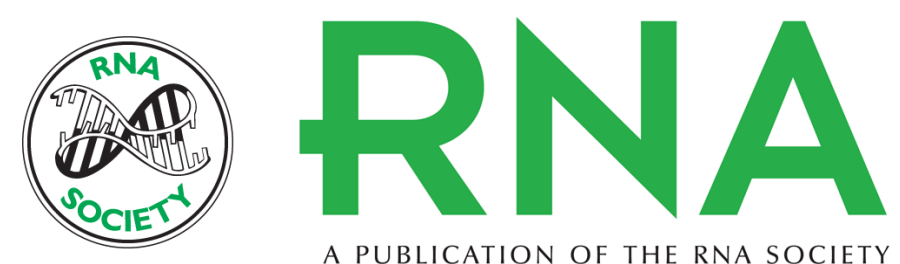

A PUBLICATION OF THE RNA SOCIETY

\section{Formation of a stalled early intermediate of pseudouridine synthesis monitored by real-time FRET}

Martin Hengesbach, Felix Voigts-Hoffmann, Benjamin Hofmann, et al.

RNA 2010 16: 610-620 originally published online January 27, 2010

Access the most recent version at doi:10.1261/rna.1832510

\section{References This article cites 44 articles, 16 of which can be accessed free at: http://rnajournal.cshlp.org/content/16/3/610.full.html\#ref-list-1}

\section{License}
Email Alerting Receive free email alerts when new articles cite this article - sign up in the box at the Service top right corner of the article or click here.

